
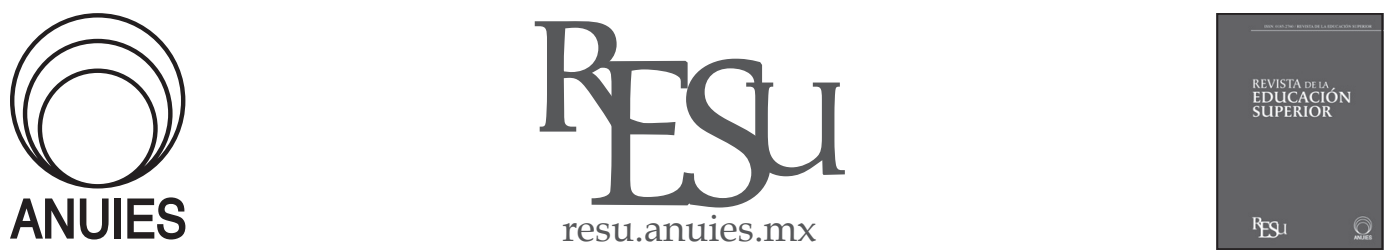

Revista de la Educación Superior 47 (185) (2018)

ARTÍ́CULO

\title{
La coordinación universitaria como problema y como necesidad: debates políticos, propuestas y experiencias en Argentina (1885-1930)*
}

\author{
Public university coordination as a problem and a necessity: Political \\ debates, proposals and experiences in Argentina (1885-1930)
}

\section{Laura Roberta Rodríguez**}

\begin{abstract}
* El trabajo forma parte de una investigación doctoral en curso, cuyo objeto es la evolución de las formas para establecer y coordinar las políticas universitarias en Argentina en el marco del sistema establecido por la Ley de Educación Superior N N 24521/95, como parte de las transformaciones el Estado y, en particular, del papel del

Consejo Interuniversitario Nacional. La autora agradece especialmente las sugerencias y comentarios de Susana E. Vior y Ma. Betania Oreja Cerruti.

** Departamento de Educación, Universidad Nacional de Luján. Luján (Provincia de Buenos Aries), Argentina. Correo electrónico: laurobrodri@gmail.com
\end{abstract}

Recibido el 28 de noviembre del 2016; aceptado el 07 de febrero del 2018.

\section{Resumen}

Este artículo analiza los debates, propuestas legislativas y experiencias de los espacios de coordinación interuniversitaria en Argentina durante el periodo que transcurre entre la sanción de la Ley Avellaneda de 1885 y el golpe de Estado de 1930. Comienza bajo el supuesto de que un análisis crítico de la coordinación universitaria, como problema de política pública, requiere situar el fenómeno en el plano histórico, vinculándolo con procesos sociales, económicos y políticos más amplios. Con un enfoque socio-histórico, a partir del análisis de fuentes primarias y secundarias, se examinan las propuestas de reforma o de derogación de la Ley 1597/1885, tanto por iniciativa de legisladores como del Poder Ejecutivo, y describo la experiencia de los "Congresos Nacionales Universitarios" desarrollada durante el gobierno de Marcelo T. de Alvear (1922-1928). Finalmente, se explora el modo en que los debates, propuestas y experiencias identificaron la coordinación interuniversitaria como un asunto problemático.

Palabras clave: Argentina; Políticas gubernamentales; Coordinación interuniversitaria; Marcelo T. de Alvear; Congresos nacionales universitarios

0185-2760/@ 2016 Asociación Nacional de Universidades e Instituciones de Educación Superior A.C. Este es un artículo Open Access bajo la licencia CC BY-NC-ND (http://creativecommons.org/licenses/by-nc-nd/4.0/). 


\begin{abstract}
This paper analyzes the legislative proposals, debates and experiences of inter-institutional forums of public universities in Argentina, between the enactment of the Avellaneda Law in 1885 and the 1930 military coup. I begin by placing the system of inter-university coordination in historical context, by linking it to the wider economic, political and social processes. The paper uses a socio-historical perspective, based on primary and secondary sources, in order to analyze the legislative proposals to reform or abolish Law 1597/1885. I also describe the experiences of the "National University Congresses" developed during the presidency of Marcelo T. de Alvear (1922-1928). Finally, I discuss the ways in which different proposals, debates and experiences identified university coordination as a problem in need of regulation.
\end{abstract}

Keywords: Argentina; Governmental policies; Higher education coordination; Marcelo T. de Alvear; Congresos nacionales universitarios

\title{
La coordinación interuniversitaria como problema político en el seno de un proceso histórico-social
}

$\mathrm{E}_{\mathrm{t}}^{\mathrm{n}}$

ntre 1983 y 1989 las cuestiones de la coordinación y el gobierno del sistema universitario argentino fueron resignificadas como un capítulo de la recuperación democrática. Sin embargo, en el marco de las tensiones generadas durante los procesos de normalización institucional (destitución de funcionarios de la Dictadura, concursos docentes y recuperación del gobierno colegiado), sumado al crecimiento fuerte de la matrícula por la apertura al ingreso "irrestricto", la crisis político-económica de fines de la década de 1980 terminó frustrando el proyecto que planteaba la construcción, por parte de los propios universitarios, de un sistema de coordinación. Este proyecto se había iniciado con el decreto de creación de un Consejo Interuniversitario Nacional (CIN) - integrado por Rectores de universidades públicas - para coordinar "las políticas entre las Universidades Nacionales y de ellas con los distintos niveles y jurisdicciones de la educación de la República Argentina, la cultura y los organismos de investigación científica y técnica" (Decreto 2461/85, art. $2^{\circ}$ ). Así, durante la década de 1990, tuvo lugar en Argentina una reestructuración profunda de la Universidad, articulada por la sanción de la Ley de Educación Superior (LES) en 1995, una de las normas componentes de la reforma educativa neoliberal y neoconservadora realizada durante los gobiernos de Carlos Menem. Además de establecer por primera vez una norma para 
todo el espacio de educación postsecundaria, con tradiciones de gobierno y de coordinación altamente heterogéneas, la LES instituyó una estructura de coordinación basada en la superposición de organismos colegiados sin poder suficiente para definir por sí mismos las líneas de política, y sin recursos económicos ni infraestructura para desarrollar actividades de largo plazo o de gran complejidad técnica. En ese proyecto sectorial, que formaba parte de una política más amplia cuyo núcleo era el ajuste estructural, una parte del problema de la coordinación quedó ligado a los criterios cuasi-mercantiles de competitividad, de gerencialismo y de disminución del financiamiento público.

El proceso fue acompañado por una importante producción de investigaciones sobre el gobierno y la coordinación universitaria. En una primera fase, las investigaciones nacionales intentaron generar conocimiento para comprender - apoyando o combatiendo - el proceso de implantación de una reforma sectorial de corte neoliberal y neoconservador. Ya sobre el siglo XXI, los estudios se concentraron en el análisis de los efectos y abordaron en qué medida las "nuevas" políticas, aplicadas a partir de 2003 bajo las presidencias de Néstor Kirchner y Cristina Fernández, en tanto que habían mantenido la legislación de la década de 1990, continuaban o modificaban el rumbo establecido.

En términos generales, el tratamiento de los antecedentes de gobierno y de coordinación anteriores al régimen establecido por la LES parte de un supuesto que es, a la vez, una hipótesis interpretativa: las políticas universitarias de los gobiernos nacionales a lo largo del siglo xx podrían entenderse como oscilando entre dos polos, por un lado, la coordinación política concentrada en manos del Poder Ejecutivo Nacional (PEN)/Ministerio de Educación (MEd) y, por otro, la delegación de importantes aspectos de la coordinación en órganos académicos colegiados representativos de las universidades. Incluso en la actualidad es usual que estos "modelos" contrastantes sean asociados con concepciones sobre lo que se define como "el problema de la relación entre Estado y Universidad", ${ }^{1}$ concepciones que habrían caracteriza-

\footnotetext{
${ }^{1}$ En la literatura sobre política universitaria argentina, y por causas cuyo análisis excede a los propósitos de este artículo, es habitual tratar las relaciones entre la Universidad y las fracciones gobernantes y/o el Gobierno Nacional en sentido amplio (en tanto segmento institucional diferenciado dentro del Estado Nacional que incluye a los tres poderes), o restringido (sólo en tanto Poder Ejecutivo), definiéndolas como "relaciones entre Estado y Universidad", vinculándolas con el tratamiento del problema de la "autonomía universitaria". Creo que esta caracterización forma parte de una teoría del Estado y de la política pública que no permite analizar y comprender adecuadamente los problemas de coordinación y de gobierno interuniversitarios, en tanto que opaca
} 
do, respectivamente, a los gobiernos peronistas y radicales. La aparición de un organismo específico en la primera ley universitaria del peronismo (Ley 13.031 de 1947), denominado Consejo Universitario Nacional (CUN), suele ser presentada como el hito fundacional de esa alternancia entre los dos polos (por ejemplo: Cantini, 1997; Sánchez Martínez, 2003; Nosiglia y Mulle, 2012). ${ }^{2}$

En realidad, en tanto no se han investigado aún en forma suficiente las experiencias concretas de coordinación en distintos periodos, los análisis permiten realizar sólo algunas inferencias sobre el enfoque predominante con el que cada gobierno intentó resolverla. Por otra parte, el tratamiento de proyectos alternativos coexistentes suele tener un lugar marginal y es poco frecuente que se integren a la discusión los modos de articulación entre la política universitaria con el resto de las políticas sectoriales y sociales, las transformaciones del Estado y su aparato, o la formación social en que se integra y en la que "actúa". Dentro de esta perspectiva, el interés por la coordinación es consustancial al de comprender cómo las transformaciones en las relaciones entre Universidad y gobiernos se articulan con los cambios en la forma y las funciones del Estado, en cada coyuntura de la sociedad capitalista. Desde mi punto de vista, la tarea debe comenzar por ubicar las concepciones y experiencias de coordinación en un plano socio-histórico, vinculándolas con los procesos sociales, económicos, políticos y culturales que acompañaron su aparición como cuestión problemática y su desarrollo concreto en cada etapa. Me pregunto, por ejemplo: ¿qué factores activaron las preocupaciones por la coordinación de las actividades universitarias?; ¿qué sectores o grupos la impulsaron?; ¿qué procesos determinaron su institucionalización?; ¿el impulso emerge de los universitarios, de los funcionarios estatales, de los políticos, de todos o sólo de algunos actores?; ¿en el marco de qué condiciones y proyectos sociales, económicos y políticos?

el modo concreto de existencia de las universidades como parte integrante del Estado. Tal modo de definir la cuestión arrastra supuestos del debate universitario "histórico" reflejado en las discusiones legislativas y en la prensa en los años que precedieron a la sanción de la Ley Avellaneda, y atraviesa todo el siglo xx hasta el presente. Omitimos en este trabajo la caracterización de este concepto y la discusión sobre sus derivaciones teórico-epistemológicas para el estudio de la política universitaria.

${ }^{2}$ En realidad, el primer organismo de coordinación universitaria aparece durante la presidencia de Agustín P. Justo. En enero de 1935, siendo Manuel de Yriondo, Ministro de Justicia e Instrucción Pública, se creó un Consejo Consultivo de Universidades (Decreto 55.425), un órgano colegiado de carácter consultivo compuesto por los rectores / presidentes de las uUNN. En virtud del recorte temporal de este artículo, omitimos su tratamiento. 
En esa línea, el presente artículo analiza e interpreta la aparición y la instalación de la coordinación interuniversitaria como un problema de política pública entre la sanción de la Ley Avellaneda (1885), la crisis económica internacional de 1929 y el golpe de Estado de 1930 que derrocó al Presidente Hipólito Yrigoyen, etapa caracterizada por una clara hegemonía de la burguesía pampeana. ${ }^{3}$ A lo largo de más de treinta años es posible observar la aparición de la coordinación como problema y como necesidad, diferenciable de las preocupaciones predominantes por la democratización, la autonomía y el desarrollo de la investigación científica en las instituciones. Durante la década de 1930, esas preocupaciones se transformaron en fundamentos para la institucionalización de espacios de coordinación de las actividades universitarias como parte de una política sectorial, en un nivel en el que se había producido una significativa expansión de la matrícula en términos absolutos, acompañando procesos más generales de redefinición de las funciones del Estado (liberal). Mi hipótesis radica en que ese proceso quizá está vinculado con el desarrollo de concepciones contrastantes sobre las formas de coordinar, portadas por grupos sociales y políticos diversos.

Para abonar dicha hipótesis, y con un enfoque teórico-metodológico provisto por los estudios socio-históricos, a partir de fuentes primarias y secundarias ${ }^{4}$ reconstruí tres dimensiones del proceso de emergencia de la coordinación interuniversitaria tanto por ser una cuestión socialmente relevante como por tratarse de un problema que debía ser atendido: 1) las propuestas de reforma o derogación de la Ley 1597/885 desde fines del siglo XIX hasta 1930, tanto por iniciativa de legisladores como del Poder Ejecutivo; 2) los ejes del debate en los periódicos, publicaciones académicas, discursos de funcionarios públicos, autoridades y docentes universitarios, y documentos oficiales del periodo; 3) algunas experiencias concretas de generación de espacios institucionalizados de trabajo y de debate interinstitucional en los que se pusieron en juego demandas de coordinación. ${ }^{5}$

\footnotetext{
${ }^{3}$ Seguimos aquí el esquema interpretativo de Ansaldi (1994a; 1994b), quien define el periodo que va de 1880 a 1930 como la "etapa de hegemonía burguesa", con dos fases: una organicista (1880-1916), y una pluralista (1916-1930). El golpe de Estado de 1930 anuncia el pasaje a una etapa de "crisis orgánica", con distintas fases, entre las que el peronismo representa un primer intento de resolución de la crisis hegemónica (1943-1955).

${ }^{4}$ En el sentido en que son definidas habitualmente por la historiografía y la Sociología Histórica.

${ }^{5}$ Se toman aquí los proyectos compilados por la Dirección de Información Parlamentaria del H. Congreso Nacional. Ellos son: Proyecto de Reorganización Universitaria de Eliseo Cantón de 1904, Proyecto de Ley Orgánica de Instrucción Pública (Proyecto Yrigoyen/ Salinas, 1918), Proyecto de Ley Universitaria del Diputado Matías Sánchez Sorondo (1923,
} 


\section{Las prioridades de la "agenda universitaria" en la fase organicista de la hegemonía burguesa (1880-1916)}

Durante el periodo 1880-1916 se construyó el Estado argentino moderno y se definió la orientación agroexportadora de la economía; como señala Graciarena (1984), se trató de un Estado oligárquico en sus fundamentos sociales, aunque liberal en su arquitectura institucional; su expresión política fue el Partido Autonomista Nacional (PAN) y el "unicato" - el gobierno de los "notables" - , un formato burgués de representación en el que los dirigentes políticos provenían tanto de la fracción dominante como de fracciones aliadas; fue un periodo dinámico de conformación y de re-configuración de fuerzas. En el plano político se expresó en el enfrentamiento entre grupos ligados al socialismo, al anarquismo, al conservadurismo o al liberalismo social, que cuestionaron el régimen oligárquico liberal fundacional. Como apunta Sarte1li (2011), hasta 1930 la renta agraria extraordinaria permitió el desarrollo de un mercado interno abastecido por una industria local dependiente de ella, a través de subsidios directos, desgravaciones impositivas, impuestos a las importaciones, etc., con escasa capacidad competitiva en el mercado mundial. Las tensiones derivadas de la fuerte expansión demográfica, el crecimiento económico bajo el modelo agro-exportador-dependiente y una primera fase de "industrialización sin revolución industrial" (Murmis y Portantiero, 1968), más sus efectos en términos de diversificación de las relaciones sociales por la aparición de fracciones burguesas (agraria, no agraria) con sus divisiones y estratos, determinaron la escisión de la burguesía en un ala liberal (social) reformista y otra conservadora. La aparición de las "clases medias" y obreras urbanas sumadas a la actividad de socialistas y anarquistas acentuó las contradicciones en el plano político, las cuales desembocaron en la Revolución de 1890 y en la conformación de los partidos radical y socialista.

El bloque hegemónico, bajo la dirección de la burguesía bonaerense, articuló a las burguesías provinciales pero no logró subordinar al resto de las fuerzas sociales (verbigracia, fracciones rurales subalternas del interior y la pequeña burguesía urbana). Por esa razón, en esta etapa, la hegemonía burguesa puede ser considerada "dirigente" sólo en lo económico (y en menor medida en lo cultural) y "dominante" en lo político (Ansaldi, 1994b). Esta

1925), Proyecto de Ley Universitaria del Diputado Pedro Cossio (1929). Ver: Dirección de Información Parlamentaria (2010). Educación Superior. Antecedentes para la Reforma. Buenos Aires: HCDN. 
debilidad estructural llevó a una forma de ejercicio del poder altamente concentrada y excluyente; la hegemonía no se hizo efectiva a través de una regulación de las diferencias, sino "procesándolas mediante la uniformación (siempre que se pu[diera]) o la exclusión (cuando no se p[odía] uniformar)" (Ansaldi, 1994a: 117). A fines del siglo xIx, la burguesía resolvió el problema de su dominio político unificándose en el Estado y en algunas corporaciones de la sociedad civil (la Sociedad Rural, la Unión Industrial y la Bolsa de Comercio, por ejemplo). Por ello, puede calificarse de "organicista".

Junto con la Ley de Educación Común (1884), la Ley Avellaneda (1885) fue la expresión de esa configuración-reconfiguración de fuerzas en la cúspide de un sistema educativo público en expansión. La educación se convirtió en uno de los ejes elegidos para construir a la nación en el Estado oligárquico, arrebatando espacios ocupados primordialmente por la iglesia católica. Así, entre 1869 y 1914, la tasa de escolarización de la población de 6 a 13 años pasó del 20\% al 48\% (Fernández et al., 1997). Según las estadísticas del Ministerio de Educación, entre 1910 y 1918, la matrícula de los colegios secundarios (predominantemente colegios nacionales) creció un 160\% (alrededor de 46800 estudiantes). Entre 1883 y 1898, la matrícula universitaria se cuadruplicó, pasando de 762 a 2928 estudiantes en las dos universidades existentes (Tedesco, 1986 [1970]); entre 1910 y 1918, creció un 82\%, llegando a los 8634 matriculados, cifras que no pueden ser explicadas sin suponer cambios en la composición social del alumnado, integrado en proporciones crecientes por jóvenes provenientes de los estratos medios urbanos y de origen inmigrante. Hacia principios de siglo, las demandas y respuestas con que diversos sectores intentaron resolver la "cuestión social" llevaron hacia una fase "pluralista" (sanción de la Ley Sáenz Peña y ascenso de gobiernos radicales). La activación de los conflictos políticos intra-oligárquicos entre fracciones de la burguesía del interior y de la pampa húmeda contribuyó a la constitución de un nuevo bloque de fuerzas liderado por los liberales reformistas, para quienes la Universidad siguió siendo el semillero de los elencos gobernantes, pero también un espacio donde la actividad científica estaba llamada a contribuir a la mejora social, a la modernización del país y a la reforma política (Portantiero, 1978; Favaro y Morinelli, 1991; Zimmerman, 1992 y 1995; Suasnábar, 2009). Este pasaje no se dio sin la resistencia de los sectores más conservadores; en el plano educativo se manifestaron como debates alrededor de la "crisis" de la educación pública e impulsaron proyectos de reforma; con el argumento de "ajustar" la educación a los objetivos de la modernización y de la industrialización, propusieron modificaciones en la estructura (creación de la escuela intermedia, diversificación de los estudios 
secundarios, creación de circuitos cerrados de formación profesional), en el curriculum y en el gobierno del sistema, aspectos que pueden ser considerados como intentos de "cierre" a los grupos en ascenso (Cucuzza, 1985; Tedesco, 1986 [1970]; Puiggrós, 1996). ${ }^{6}$

El periodo que media entre la sanción de la Ley Avellaneda y el estallido del movimiento reformista en Córdoba (1918) es usualmente caracterizado como el de la "Universidad Liberal-Oligárquica" (Cano, 1986; Fernández Lamarra, 2003; Buchbinder, 2005). Las apreciaciones clásicas postulan el carácter fluido de los vínculos de la Universidad con las fracciones gobernantes, ideas sintetizadas en las frases "de la universidad al poder y del poder a la universidad" (Cano, 1986), o la "homogeneidad política e ideológica entre Estado y Universidad" (Fernández Lamarra, 2003). Es cierto que para esas fracciones, la Universidad - y en particular la Facultad de Derecho - fue el espacio de formación de sus miembros (De Imaz, 1969; Buchbinder, 2012), y también de sus elencos subalternos; del mismo modo fue uno de los espacios de realización de la dominación oligárquica pues, como señala Ansaldi, ella misma requirió la ampliación de los espacios para forjar las "alianzas de notables" hacia "otras instituciones semi-públicas o prolongación pública del espacio privado (clubes de diverso tipo) y/o esencialmente públicas ("partidos' y sobre todo el Parlamento)" (Ansaldi, 1991: 3). ${ }^{7}$ No obstante, creo que la caracterización de "Universidad Liberal-Oligárquica" no debería obturar el análisis de las contradicciones que pronto emergieron y que cuestionaron ese proyecto ideal - de los grupos dominantes y de distintas fracciones - que pugnaba por mantener el control de los recursos económicos, de las fuentes del poder social y del acceso al control del Estado (lo cual implicaba, también, el control de la Universidad) (Graciarena, 1984); por otra parte, tampoco debería ser entendida como una descripción de la condición social, o de

\footnotetext{
${ }^{6}$ Los proyectos más importantes fueron los presentados por los Ministros O. Magnasco (1899) y C. Saavedra Lamas (1916).

${ }^{7}$ Para una discusión teórica sobre el término "oligarquía" y su uso en el análisis político de esta etapa de la historia argentina, en particular sus referencias a la discusión clásica sobre la asimilación o la imbricación entre "elites económicas" y "elites políticas" y el análisis de las formas de procesar conflictos "intra-oligárquicos", ver Botana (1998: 60 y ss.). Por su parte, Ansaldi (1991) señala el uso ambiguo y omnicomprensivo del término en las Ciencias Sociales. Consideramos que este problema está presente en las investigaciones sobre la Universidad que utilizan periodizaciones en las que se alude a la etapa de la "universidad oligárquica", sin problematizar el concepto a la luz de la efectiva diversificación de la composición social del alumnado, y/o también en aquellas que utilizan la categoría de "elite", en muchos casos haciendo un uso laxo de un concepto que ha sido - y sigue siendo - objeto de extensos debates teóricos.
} 
clase, de los universitarios, o de la institución, sino como la materialización dentro de las universidades de la forma de dominación política coercitiva y excluyente que se ejercía en un espacio social más amplio.

Así como la hegemonía organicista de la burguesía bonaerense fue puesta en entredicho a partir de 1890, también la hegemonía del proyecto oligárquico de Universidad había comenzado a resquebrajarse (Terán, 2000; Rojkind, 2007). Los conflictos y contradicciones derivados del carácter oligárquico del gobierno universitario se expresaron en variados episodios: enfrentaron a las corporaciones (Academias) con docentes y estudiantes, y a las universidades con varios gobiernos nacionales. A su vez, estos conflictos acompañaron y fueron estimulados por transformaciones que tenían lugar en los niveles no obligatorios del sistema educativo, entre ellos: la sostenida expansión de la enseñanza media, en particular aquella definida como estudios propedéuticos para la Universidad; el desarrollo y la consolidación de la actividad de los médicos, abogados, ingenieros, y otros profesionales con independencia del desempeño de la función pública; la lenta conformación de una "profesión" docente y científica. La temprana aparición de fricciones entre las universidades y los gobiernos por cuestiones presupuestarias se combinó con conflictos derivados de las demandas políticas y sociales de los grupos que se incorporaban a las aulas universitarias. Muestra de ello fueron la creación de universidades provinciales (La Plata, Santa Fe), la diversificación de la composición social del alumnado, el surgimiento y el desarrollo de las federaciones estudiantiles, los conflictos y huelgas en las Facultades de Medicina y Derecho en la Universidad de Buenos Aires en 1903-1906 (que llevaron a la reforma de sus estatutos para aumentar la participación de los docentes), elementos interpretados por todos los autores como el antecedente de la Reforma Universitaria de Córdoba (Halperín Donghi, 1962; Chiroleu, 2000; Biagini, 2000; Buchbinder, 2005; Ortiz y Scotti, 2008; García, 2010). Interpretaciones contrastantes sobre la autonomía universitaria se entretejieron con distintas ideas sobre la organización de las instituciones (por ejemplo, la mayor o menor independencia de las Facultades respecto de los Consejos Superiores) y con los principios y formas que debían asumir las relaciones entre las universidades y "el Estado" (por ejemplo, la conveniencia de mantener y/o reforzar el control estatal, de separar los títulos académicos de los habilitantes, de limitar el número de "doctores" y de instituciones, o de angostar los canales de acceso por medio de la supresión de los colegios nacionales en provincias y su sustitución por modalidades "prácticas"). ${ }^{8}$

\footnotetext{
${ }^{8}$ Por ejemplo, el proyecto de Antonio Bermejo, Ministro de Justicia e Instrucción Pública (Presidencia de José E. Uriburu (1897).
} 
Después de la crisis política y económica de 1890, la fracción más conservadora de la burguesía intentó saldar los conflictos intraoligárquicos, los cuales se expresaban políticamente como discusiones sobre la manera de procesar las reivindicaciones de sectores sociales en ascenso (Zimmermann, 1992 y 1995). En el plano educativo intentó avanzar con propuestas de reforma, como fue el caso de las presentadas por dos de los Ministros de Instrucción Pública durante el segundo gobierno de Julio A. Roca: Osvaldo Magnasco y J. R. Fernández. En lo que respecta a la Universidad, las principales preocupaciones estuvieron relacionadas con la "autonomía externa" (de la institución universitaria respecto del Estado y de las Academias) e "interna" (de las Facultades respecto del Rectorado y el Consejo Superior). En 1899, el ministro Osvaldo Magnasco presentó un proyecto de ley orgánica de educación que contenía un apartado dedicado a las universidades ("Plan de Instrucción General y Universitaria"), el cual por un lado postulaba la total autonomía y la libertad de las mismas en lo que respecta a los estudios científicos, mientras que por otro reivindicaba el papel principal del Estado en el control de la formación y de la habilitación de los profesionales: la Universidad no era un "poder político" sino un "poder científico"; por lo tanto, el Estado era la "representación política de la sociedad", el encargado de elaborar "los planes universitarios", así como de "imprimirles carácter, darles tendencia y organizar la enseñanza de esta clase en orden a los fines sociales", pues "ninguna constitución de la tierra antigua o moderna ha puesto en manos de este género de corporaciones, sino, al menos siempre virtualmente, en manos de la entidad gubernamental" (Congreso Nacional, 1899: 111). El ministro Magnasco afirmaba que la "alta ciencia política" aconsejaba que el Estado asumiera "la erección o la autorización de estas nobles fábricas, el establecimiento del plan de estudios, la distribución general de la enseñanza, la imposición de los requisitos más importantes, y, en su caso, la confirmación del personal docente, y siempre la del título que acredite la presunción legal de competencia" (Congreso Nacional, 1899: 111). ${ }^{9}$

Sobre el final del gobierno de Julio A. Roca, bajo el marco de los disturbios y huelgas estudiantiles en las Facultades de Derecho y de Medicina de la Universidad de Buenos Aires, los sectores liberales reformistas presionaron para modificar la Ley de 1885, pero en sentido diferente al pretendido por

\footnotetext{
${ }^{9}$ Conviene aclarar que con posterioridad a la Ley Avellaneda, siguió vivo el debate por la interpretación del Art. 67 de la Constitución Nacional referido a la atribución del Congreso para dictar "planes de instrucción general y universitaria". Para algunos, se trataba de Planes de Estudio; para otros, líneas de política. Ver, por ejemplo, el debate parlamentario de la Ley Avellaneda en Rodríguez Bustamante (1985).
} 
Magnasco, pues en el proyecto presentado por el ministro J. R. Fernández en 1904 -que recibió el apoyo de varios liberales-reformistas con trayectoria académica y gubernativa - la preocupación principal fue disminuir el poder de las Academias y el control estatal, dando protagonismo a los profesores. ${ }^{10}$ Por ejemplo, el Dr. Nicolás Matienzo (entonces profesor de la Facultad de Filosofía y Letras de la Universidad de Buenos Aires) calificó la Ley de 1885 como una pieza caduca y comentó positivamente el proyecto, aprobó la separación entre títulos académicos y habilitantes, y defendió la autonomía económica, académica e institucional de la Universidad respecto del Estado. ${ }^{11}$ Ese año también presentaron proyectos los diputados conservadores Francisco Oliver (abogado, docente de la Facultad de Derecho de la UBA y miembro del Partido Conservador de la Provincia de Buenos Aires) y Eliseo Cantón (Partido Conservador de Tucumán, médico y miembro de la Academia de Medicina en la Universidad de Buenos Aires). En la propuesta de Oliver, las facultades adquirían total independencia. ${ }^{12}$ El proyecto de Can-

${ }^{10}$ Unos años antes (hacia 1899), en artículos escritos en la Revista de Derecho, Historia y Letras, Juan R. Fernández se había manifestado a favor de la separación entre títulos académicos y habilitantes, reservando esta última función al Estado: “[...] oponer la verdadera universidad, como órgano de la sociedad, a la falsa universidad actual que sólo es una repartición del Estado, o peor aún, una dependencia del Poder Ejecutivo [...] la creación que proponemos en la erección de las universidades libres es la de la independencia de las universidades del Estado, cuando éstas son capaces de constituirse en centros autónomos y llenar su misión [...] Las universidades libres tendrán, pues, sus funciones propias dentro del organismo social, como el Estado mismo, y las universidades, lo veremos más tarde, son tan necesarias para el Estado como éste lo es para las universidades". Citado por: Barsky, O. y Del Bello, Juan C. (2007). La universidad privada argentina. Buenos Aires: Libros del Zorzal, 50-51.

${ }^{11}$ Decía Matienzo: “La Universidad no es una escuela profesional sino un laboratorio de cultura intelectual y moral. Si el Estado quiere acordar valor profesional a los diplomas universitarios, que lo haga en buena hora, pero si no lo hace, la ciencia y el arte no habrán perdido nada y la universidad habrá conservado su dignidad" [Matienzo, José N. (1904). La Reforma Universitaria. Revista de la Universidad de Buenos Aires. Año 1, Tomo I, 410]. Abogado graduado en la Universidad de Buenos Aires, Matienzo era en ese momento profesor de Lógica e Historia de la Filosofía (incorporando en su cátedra la presentación de la obra de J. Stuart Mill), y se había desempeñado como juez en el fuero Civil de La Plata; fue Procurador General de Justicia de Yrigoyen y Ministro del Interior de Marcelo T. de Alvear. Para una breve reseña biográfica de Matienzo, puede consultarse: Frías, P. J. (1999). Nicolás Matienzo: una semblanza. Anales de la Sociedad Argentina de Ciencias Morales y Políticas. Tomo xxvIII, 247-252.

12 “La base principal del proyecto consiste en prescindir de esta gran organización que se llama universidad, con sus funcionarios superiores llamados rectores y consejo superior universitario, dejando solamente como entidades existentes las facultades con 
tón, "sobre la autonomía de las universidades de Buenos Aires y Córdoba", 13 optaba por mantener cierta unidad institucional a la vez que intentaba separar a la "oligarquía" académica de sus lazos con el gobierno, eliminando el carácter vitalicio de los académicos y proponiendo la autonomía "técnica y administrativa" de las universidades, medio ideal para lograr su "libertad absoluta"; proponía además que la Universidad absorbiera la facultad del Poder Ejecutivo de nombrar a los profesores titulares, y la del Poder Legislativo de dictar los planes de estudio. ${ }^{14}$ La ley no fue reformada pero, en 1906, se aprobaron nuevos estatutos que garantizaron el gobierno de los profesores y permitieron la aparición de Consejos Directivos renovables, dejando en un papel secundario a los académicos vitalicios.

Al analizar estos debates, abstrayendo la cuestión del dominio de las Academias, ${ }^{15}$ dentro de la fracción liberal-conservadora se distinguen dos grupos: uno de ellos defiende la "libertad absoluta" de las universidades respecto del Estado; en el otro comienzan a tomar cuerpo las concepciones defensoras de su intervención ("coordinación desde arriba"), como la mejor manera de garantizar que cumplieran su función específica en la materialización del proyecto político gubernamental. Estos objetivos quedaron rebasados por las reivindicaciones del movimiento de la Reforma Universitaria, que puso en la lista de prioridades la democratización interna de las instituciones, la incorporación de sectores en ascenso y el compromiso social; fue un momento de apertura pluralista que, simultáneamente, activó cierres con-

sus autoridades propias". Diario de Sesiones de la Cámara de Diputados, 1904, Tomo I, 179 a 184, citado por Ortiz y Scotti, 2008: 30.

${ }^{13}$ Cámara de Diputados. Acta de la Sesión Ordinaria N 1, de 6 a 9 de mayo de 1904. Libro 45. Disponible en: http:/ / www.archivolegislativo.com.ar:8080/gsdl/cgi-bin/?e=d01000-00---off-0incunabl--00-1----0-10-0---0---0direct-10---4-------0-11--11-es-50---20-home--00-3-1-00-0--4--0--0-0-11-00-0utfZz-8-00\&a=d\&c=incunabl\&cl=CL2.1.50\&d=D5038 [consultado el 20 de marzo de 2015).

${ }^{14}$ Decía Cantón: “[...] yo querría una verdadera república universitaria, completamente libre e independiente de todo otro poder superior... una universidad que tenga facultades ejecutivas y legislativas; que conste de un poder ejecutivo que se llame rector, con la facultad de nombrar a los profesores y que tenga un cuerpo deliberativo, consejo superior, con la facultad de discutir y de sancionar los presupuestos y los planes de estudios de las diferentes facultades" (Dirección de Información Parlamentaria, 2008: 231).

${ }^{15}$ Dejamos aquí de lado todos los debates conectados con éste, relativos a la independencia financiera y el sostén económico de las instituciones, que puede recorrerse en todas las discusiones legislativas desde la aparición de los primeros proyectos de ley universitaria a fines de siglo XIX. 
servadores en el terreno educativo en general, y universitario en particular ${ }^{16}$ (Portantiero, 1978; Vior, Misuraca y Más Rocha, 2001 y 2005).

\section{La introducción de la "coordinación universitaria" como problema de política universitaria en la fase pluralista (1916-1930): Consejos y Congresos}

Durante la primera década del siglo xx, además de intentar limitar el número de abogados $-\mathrm{y}$ otros profesionales - , los gobiernos nacionales se negaron a otorgar el carácter habilitante a los títulos otorgados por las universidades provinciales de Santa Fe y La Plata, resistiendo a la creación de nuevas casas de estudios y argumentando problemas presupuestarios (García, 2010). En un discurso pronunciado en la Universidad de La Plata, el Ministro de Instrucción Pública bajo el gobierno de Victorino de la Plaza, Carlos Saavedra Lamas, manifestó su preocupación por la inadecuación de la Ley Avellaneda y la falta de regulación de las atribuciones entre nación y provincias en la creación y el sostén de las universidades. La universidad provincial competía "con las nacionales, no sólo en la disputa del subsidio, sino también en el prestigio y en la validez de los títulos que otorga" (Saavedra Lamas, 1916: 13). La cuestión, resuelta alrededor de 1909 otorgando la validez nacional a sus títulos - sujeta a la adopción de los planes de estudios de las nacionales - , era para Saavedra Lamas una "nacionalización incompleta"; el minis-

\footnotetext{
${ }^{16}$ Puede ser ilustrativo recordar que la obra "M' hijo el Doctor" de Florencio Sánchez, se estrenó en Buenos Aires en el Teatro de la Comedia, en agosto de 1903. Saguier y Meabe (2013: 479-480) proporcionan datos sobre las transformaciones en la composición social de los estudiantes de algunas facultades de la Universidad de Buenos Aires durante los conflictos de 1906: “El decano de medicina Pedro Lagleyze, hijo de inmigrantes franceses, declaraba ... que: «Los estudiantes de medicina no eran como los de derecho»... provenían de estratos socio-étnicos más subalternos que los de derecho, pues muchos de ellos eran hijos o nietos de inmigrantes, especialmente de familias italianas, o procedentes del interior provinciano... Pertenecen dichos estudiantes, «...a esferas sociales más bajas y por eso le pedía al Jefe de Policía que no fueran los vigilantes con guantes blancos y que mandara un comisario de bastante energía»." Romero (2004) aporta artículos periodísticos de la época que discuten proyectos legislativos de aumento de las tasas y matrícula de la UBA que son explícitamente interpretados como intentos de cierre a esos sectores sociales en ascenso.
} 
tro proponía la nacionalización definitiva y la prohibición de la creación de nuevas instituciones universitarias provinciales. ${ }^{17}$

En un momento en que la situación internacional imponía fuertes restricciones económicas, el peso del presupuesto universitario en el gasto público era esgrimido para limitar la expansión del número de instituciones. En esta coyuntura apareció por primera vez la iniciativa de una instancia de coordinación supra-institucional, un "Consejo superior de orden nacional" con la finalidad de administrar y de aplicar el "subsidio" votado anualmente por el Congreso, considerándolo como fondo común y no como fondos de cada institución. La presencia de una instancia de coordinación se presentaba como garantía de racionalidad, de armonía y de correlación, no sólo de las universidades, sino del sistema educativo como un todo, bajo la tutela de una "elite dirigente" por derecho propio, pues "[1]a instrucción... debe bajar de las universidades y penetrar en todo el tejido social hasta llegar al humus profundo de la masa popular, renovándolo bajo el impulso de las capacidades superiores" (Saavedra Lamas, 1916: 18 y 21). Criticando el carácter corporativo y particularista de la postura "autonómica" calificada como un "mutuo recelo, una especie de feudalismo altivo y hostil, demostrado en nuestros anales universitarios", señalaba la necesidad de establecer "un espíritu de correlación en su orden interno y de interdependencia en su actividad exterior" (Saavedra Lamas, 1916: 14-15).

Para los sectores reformistas (académicos y/o gobernantes), el acento estaba puesto menos en la coordinación y más en la reforma interna de las instituciones, reflejo del necesario reajuste para incorporar la Universidad al

\footnotetext{
${ }^{17}$ Decía el ministro que "la ley nacional que rige la vida de nuestras universidades puede coartar el número excesivo de institutos universitarios, improvisados a veces sin criterio y sin conciencia, en las incidencias de una discusión presupuestaria, pero rara vez con la vitalidad y con el legítimo derecho de las universidades de Tucumán y del Litoral que, al ser nacionalizadas, deberían clausurar en mi sentir el ciclo de todo otro posible advenimiento" (Saavedra Lamas, 1916: 13). Recuérdese que la Universidad de Tucumán fue "nacionalizada de hecho" por la inclusión de una partida específica en el presupuesto nacional de 1921, y la transferencia realizada por su rector de entonces, Juan B. Terán, de los bienes de la universidad a la Nación ad referéndum de la Legislatura provincial, que nunca se pronunció. La ley que formaliza la nacionalización es la 1566 de 1934 (Vignoli, 2004). La Universidad del Litoral, creada sobre la Universidad Provincial de Santa Fe, fue nacionalizada en 1919 (Busaniche, 1977). En ambos casos, las demandas de nacionalización son anteriores a 1918, y fundamentalmente se originaron en la dificultad para garantizar el financiamiento exclusivamente provincial, y la reticencia del gobierno nacional para conceder el carácter habilitante a los títulos que otorgaban.
} 
nuevo esquema de poder triunfante en $1912 .{ }^{18}$ Es entendible, entonces, que en la diversidad de documentos y declaraciones - de referentes y defensores - del movimiento universitario reformista, la coordinación no apareciera como necesidad específica. Recordemos además que durante el desarrollo mismo del conflicto (Córdoba, 1918), el Poder Ejecutivo presentó un proyecto de ley de educación con un apartado correspondiente a las universidades, en el que se introducían modificaciones en el gobierno interno: se incorporaba un graduado en los Consejos Directivos en representación de los estudiantes, y se conformaba el Consejo Superior sólo con profesores de las distintas categorías (ningún miembro de Academias). Pero el proyecto no incluyó instancia alguna de coordinación, de modo que la representación estudiantil y la periodicidad de cátedra fueron introducidas, como en 1906, mediante reformas estatutarias.

Durante el gobierno de Marcelo T. de Alvear (1923-1928), la reconfiguración de los apoyos políticos del radicalismo antipersonalista, por su acercamiento a sectores conservadores de la burguesía, generó retrocesos de esas "conquistas" en casi todas las casas de estudios: durante la década de 1920, varias universidades fueron intervenidas aprovechando los conflictos derivados del co-gobierno, y se apoyaron reformas de los estatutos con la finalidad de limitar la participación estudiantil. ${ }^{19}$

\footnotetext{
${ }^{18}$ Señala Graciarena (1971: 75.76): “La universidad había estado ligada muy de cerca con el sistema de dominación que circunstancialmente periclitaba [...] La función del movimiento reformista fue actuar como detonante impulsando una transformación de una universidad que ya no se ajustaba al nuevo esquema de poder, en el que se destacaba la gravitación de los emergentes grupos urbanos de clase media fuertemente inclinados a hacer sentir sus presiones en el terreno educacional y a valerse de ella como un instrumento de movilidad social".

${ }^{19}$ Por ejemplo, el diputado Sánchez Sorondo presentó en 1923 un proyecto suprimiendo la representación estudiantil, para apartar a la juventud de "las sugestiones morbosas de politiquería electoral universitaria, la más nociva y deletérea de las politiquerías" (Dirección..., 2010: 259). Previamente (1914-1918) había sido Director General de Escuelas de la Provincia de Buenos Aires (en el segundo gobierno de Marcelino Ugarte), y diputado durante parte del primer gobierno de Yrigoyen. Participó activamente en el golpe cívico-militar del 1930, y fue nombrado Ministro del Interior por el General Uriburu, cargo desde el que desarrollará una violenta política de persecución a comunistas, anarquistas y opositores. Fue senador por el Partido Conservador de la Provincia de Buenos Aires durante la presidencia de Agustín P. Justo, auspiciando la Ley de Represión de Actividades Comunistas.
} 
En 1923 el Ministro de Justicia e Instrucción Pública, Celestino Marcó, ${ }^{20}$ elevó al Congreso un proyecto de Ley Orgánica de Enseñanza, señalando "el grave problema educacional argentino que es, sin disputa, el de mayor urgencia y mayor significación".${ }^{21}$ Apelando a la descentralización y a la necesidad de un mejor balance entre "los deberes del Estado y los derechos de la sociedad", propuso un sistema de subvenciones a escuelas/colegios particulares; autorizaba las universidades libres (privadas) - aunque sin el derecho a otorgar títulos habilitantes - con la posibilidad de asistirlas mediante fondos públicos; ${ }^{22}$ omitía toda mención al co-gobierno; establecía el carácter contingente del financiamiento público "hasta tanto [las universidades] pu[dieran] cubrir sus presupuestos con recursos propios" (Art. 272); también asimilaba al docente universitario a los otros niveles educativos y, además, proponía una estructura para el gobierno y la coordinación del sistema a partir de cuatro consejos autónomos (de enseñanza primaria, secundaria, profesional y universitaria) con la participación de representantes de la enseñanza particular/libre. Así, se volvió a plantear el tema de la coordinación, esta vez bajo la forma de un Consejo Nacional Universitario, haciéndolo responsable de la "superintendencia sobre todas las universidades de la república" (Art. 16); al igual que el resto de los Consejos, dependía del Ministerio de Instrucción Pública; tenía un presidente nombrado por el PEN con acuerdo del Senado y cuatro vocales - dos por el Ministerio de Instrucción Pública, uno por las instituciones "oficiales" y otro por las instituciones

${ }^{20}$ Celestino Marcó fue un radical antipersonalista oriundo de Entre Ríos, provincia de la que fue gobernador entre 1918 y 1921. Fue Ministro de Justicia e Instrucción Pública de Marcelo T. de Alvear entre 1922 y 1923. A lo largo de su trayectoria política estableció lazos con sectores conservadores y católicos como Atilio D’ell Oro Maini, ligado a la experiencia frustrada de la primera universidad católica (1910-1922). Probablemente esto explique la introducción de universidades libres en el proyecto de Ley Orgánica de Enseñanza. Para una descripción de la actuación de los intelectuales católicos durante el gobierno de M. T. de Alvear, ver: Altamirano, C. (2008: 355 y ss.).

${ }^{21}$ M. T. de Alvear. Fundamentos del Proyecto de Ley Orgánica de Educación. En: Congreso Nacional. Cámara de Diputados. Diario de Sesiones. Sesión Ordinaria No 57, 25 de septiembre de 1926, pp. 397 y ss.

${ }^{22}$ No puede descartarse que la incorporación de estas regulaciones hayan estado relacionadas con el cierre de la primera universidad privada argentina, la Universidad Católica de Buenos Aires, que desarrolló actividades entre 1910 y 1920 abriendo una Facultad de Derecho; cerró "al no poderse conseguir una ley de reconocimiento de títulos" (Derisi, 1983: 16). El Estado Nacional ya otorgaba subsidios a instituciones educativas privadas: la Universidad Popular de La Boca - si bien no era propiamente una universidad - recibía, hacia 1920, ayuda financiera del Estado (Páez de la Torre, 2004). 
"libres" - , con la misma duración que el cargo de Presidente de la República, renovables previo al fin de cada mandato presidencial - la elección de estos dos últimos delegados se organizaba a través de un sistema electoral basado en Asambleas integradas por un delegado de cada facultad existente-; poseía atribuciones para formular el presupuesto de gastos y de recursos, auditar la administración de los fondos realizada por las universidades, inspeccionar la enseñanza y las actividades universitarias, ratificar la creación de universidades o facultades, administrar el fondo universitario, designar a los docentes y, finalmente, aprobar toda creación, supresión o reforma de los planes de estudios así como de los estatutos (indicando modificaciones o su sanción definitiva).

Los sectores social-liberales también propusieron "consejos" como una instancia de coordinación pero a partir de los principios democráticos de representación, como por ejemplo el "Proyecto de Educación e Instrucción Pública" (1925) de Guillermo Sullivan, ${ }^{23}$ que organizaba el sistema educativo desde el nivel primario al superior, cuyo gobierno general se encargaba a un Consejo Nacional de Educación e Instrucción Pública, presidido por el Ministro del ramo e integrado por un delegado del Consejo de Enseñanza Primaria, otro por el Consejo de Enseñanza Secundaria y uno más por cada Consejo de Enseñanza Superior - equivalente a los Consejos Superiores de cada Universidad - ; para la conformación de estos últimos, diseñaba un sistema electoral de representantes del claustro de docentes titulares, de docentes suplentes y de estudiantes (con representación tripartita igualitaria); cada Facultad constituía una "sección" y cada Universidad un "distrito" electoral. Los delegados al Consejo Nacional por cada universidad eran nombrados por sus respectivos Consejos de Enseñanza Superior.

La aparición de estos proyectos acompañó el desarrollo de nuevas concepciones sobre el papel del Estado, las cuales propiciaban la ampliación de sus responsabilidades para intervenir y regular las actividades sociales y económicas, transformaciones que se consideraban necesarias para enfrentar los efectos de la Primera Guerra Mundial (Persello, 2000, 2001, 2009). Dichas concepciones se fortalecieron al combinarse con críticas al "despilfarro" de los recursos públicos y a las prácticas clientelares y caudillistas de la política que interferían en la cobertura de los cargos públicos, temas que enfrentaban a anti-personalistas, conservadores e yrigoyenistas. Estos debates alcanzaron a las universidades y se reformularon como parte de las fricciones entre "re-

${ }^{23}$ Congreso Nacional. Cámara de Diputados. Diario de Sesiones. Reunión N 47, 9 de diciembre de 1925, pp. 98 y ss. 
formistas" y "anti-reformistas", es decir, una coyuntura de importante efervescencia del estudiantado universitario y de creciente visibilidad política de la actividad de federaciones y congresos nacionales, regionales o internacionales de estudiantes. ${ }^{24}$

Durante la presidencia de Marcelo T. de Alvear aparecieron propuestas y experiencias incipientes de coordinación universitaria organizadas bajo la figura de "congresos". Tal es el caso de la experiencia de los "Congresos Universitarios" implementados en 1923, que fueron una iniciativa de Benito Nazar Anchorena, entonces Presidente de la UNLP, los cuales obtuvieron el apoyo del presidente Alvear y se realizaron bajo los auspicios del PEN, con la asistencia del Ministro de Instrucción Pública (hasta 1928, Antonio Sagarna $)^{25}$ y la participación de los rectores/presidentes y decanos de las facultades de todas las universidades nacionales, e incluso de delegaciones de profesores y, en menor proporción, de estudiantes, así como de gobernadores y ministros provinciales. ${ }^{26}$ Esta composición ofrece indicios de la índole de tales encuentros, en los que confluían los sectores dirigentes del gobierno y de la academia, la "aristocracia intelectual - la única legítima - del país [...] la flor y nata de los hombres de pensamiento [que] han de dar rumbos defi-

\footnotetext{
${ }^{24}$ Estos congresos tuvieron trascendencia no sólo en el ámbito universitario sino también en el político y en la prensa de la época. El Primer Congreso Internacional de Estudiantes tuvo lugar en México en 1921. Y debe notarse que, precisamente, al mismo asistió una delegación argentina en la que tres de sus cinco miembros eran de UNLP: Héctor Ripa Alberdi (presidente de la delegación), Arnaldo Orfila Reynal y Pablo Vrillaud. Ver: Rodríguez y Vazquez (2002).

${ }^{25}$ Sagarna y Nazar Anchorena representan las dos clases (burguesía y pequeña burguesía) que mayoritariamente accedían a la universidad. Antonio Sagarna provenía de una familia de inmigrantes vascos de extracción obrera asentados en Entre Ríos; estudió en el Colegio Nacional de Concepción del Uruguay y se graduó de abogado en la unL. De trayectoria radical, fue maestro, profesor y ministro del primer gobernador radical de su provincia; Alvear lo nombró interventor en la UNC (1922), Ministro de Justicia e Instrucción Pública (1923-1928), y posteriormente Juez de la Corte Suprema de Justicia (Tanzi, 2005). Benito Nazar Anchorena estuvo al frente de la unLP dos períodos consecutivos: 19211924 y 1924-1927. Proveniente de una familia terrateniente, inicialmente vinculado al radicalismo y al reformismo universitario, luego se acercó al conservadurismo. Propició la reducción de la participación estudiantil en el gobierno colegiado. Fue interventor nombrado por el gobierno de J. E. Uriburu en la UBA (1930-31) (Vallejo, 2001).

${ }^{26}$ Al Segundo Congreso, que se realizó en Buenos Aires en 1924, asistió el mismo presidente Marcelo T. de Alvear.
} 
nidos y claros a la enseñanza superior", ${ }^{27}$ y grupos de filiación liberal social y socialistas ligados al reformismo universitario. ${ }^{28}$ Afirmaba Nazar Anchorena en 1925, al inaugurar el III Congreso con sede en la UNC, que la iniciativa había concitado el apoyo de los docentes y de las autoridades de todas las universidades (Nazar Anchorena, 1926: 76). En sentido similar se expresaría el Ministro de Justicia e Instrucción Pública, Antonio Sagarna, en el acto de apertura del Iv Congreso en la unL (Sagarna, 1926: 364).

Se realizaron cinco congresos en sedes distintas: en 1923 (UNLP), 1924 (UBA), 1925 (UNC), 1926 (UNL) y 1927 (UNT). Su objetivo declarado fue generar un foro común para el tratamiento de los temas universitarios y de interés nacional; sesionaron organizados en "secciones" temáticas ${ }^{29}$ más o menos correspondientes a las Facultades/disciplinas profesionales. Explicaba Nazar Anchorena en 1925, al abrir el III Congreso en la ciudad de Córdoba, que era "de urgente necesidad que los universitarios argentinos se conozcan para un más efectivo y provechoso intercambio espiritual", que también conocieran su país, "para tomar por el conocimiento y el amor una efectiva posesión de la Patria y adquirir la consiguiente capacidad para servirla de la mejor manera posible"; al mismo tiempo, sugería que "las universidades argentinas sean inteligente y lealmente estudiadas in situ y en su funcionamiento real, conforme a sus finalidades y posibilidades" (Nazar Anchorena, 1926: 76).${ }^{30}$ De manera similar se expresó el rector Pedro Martínez en su discurso inaugural del IV Congreso en la UNL, caracterizando el encuentro como "un grande cabildo abierto universitario", espacio de discusión que estimulaba la comprensión y la solidaridad universitarias, cuyos frutos podrían verse

27 “El Cuarto Congreso Universitario. Inauguración”. Santa Fe, sábado 23 de octubre de 1926. Disponible en: http:/ / www.santafe.gov.ar/hemerotecadigital/diario/11419/?page=1

${ }^{28}$ Luis Heyssen, dirigente del aprismo peruano que vino a Argentina a estudiar a la UNLP y llegó a la presidencia de la FULP, relató un enfrentamiento con estudiantes "conservadores" en el Congreso Universitario de 1926 ["A propósito del Congreso Universitario Anual”. Sagitario, 7, La Plata, noviembre de 1926, 126-129. Citado por Beigel (2006)]. Para un panorama más detallado del movimiento estudiantil reformista de izquierda en el contexto latinoamericano, ver: Cattáneo y Rodríguez, 2000.

${ }^{29}$ Las "Secciones" eran tres: I. Jurídica, Económica y Política, II. Humanidades y Educación, III. Química, IV. Física, Matemática y Astronómica, y v. Medicina.

${ }^{30}$ El rector de UNT, Juan B. Terán, defendería la creación de universidades particulares, cuya aparición "sería un hecho memorable, no solamente como muestra de comprensión de las necesidades más íntimas de la sociedad, sino como estímulo, emulación y sugestión para las universidades oficiales" (Terán, 1926: 86). 
con el tiempo, aunque sus resoluciones no revistieran "la obligatoriedad de la ley". Siendo las universidades "instituciones de orden social", "[c]oncordarlas es aumentarlas en proporción geométrica, es darles nuevos y mayores valores como el que cobran los materiales aislados hasta que la concepción del arquetipo levanta con ellos la coherente unidad de la fábrica" (Santa Fe, "El IV Congreso...", 24 de octubre de 1926).

El periódico provincial Santa Fe, del domingo 24 de octubre de 1926, ${ }^{31}$ enumeró los temas tratados y las conclusiones de la I Sección "Jurídica Económica y Política” del Iv Congreso. Se trataron no sólo cuestiones académicocientíficas, sino también propuestas (de profesores individuales, de equipos o de cátedras) de política pública en general, mostrando diversas visiones sobre las prioridades de la política sectorial. Se presentaron propuestas de modificación del sistema electoral nacional para introducir la representación proporcional de mayorías/minorías, reforma de las leyes sobre inembargabilidad del bien de familia para proteger los hogares modestos, recomendaciones para prohibir el voto de analfabetos, para dictar un código de Legislación Industrial y Obrera, para reformar el sistema impositivo de acuerdo con los principios de progresividad, minimum de existencia y discriminación, recomendar la formación del personal administrativo del Estado, creando institutos y escuelas de Ciencias Políticas, entre otras. También se hicieron recomendaciones estrictamente académicas, por ejemplo, "intensificar" los estudios de doctorado en las Facultades de Ciencias Jurídicas y Sociales. La Sección II, "Humanidades y Educación", aprobó por unanimidad una recomendación para "constituir la confederación de las Universidades Nacionales Argentinas (propuesto por el doctor Benito Nazar de Anchorena), ${ }^{32}$ crear cátedras de Historia Argentina Contemporánea en todas las universidades, promover la formación del profesorado universitario "teniendo en cuenta su consagración exclusiva a la investigación científica y a la cultura superior", recomendar contenidos para los cursos de Historia de la Civilización en las escuelas secundarias, así como generar un servicio de información universi-

${ }^{31}$ Ver: "El Iv Congreso Anual Universitario. Ayer iniciaron sus tareas las diversas secciones. Los temas considerados y resueltos. Diversos actos celebrados". Santa Fe, 24 de octubre de 1926. Disponible en: http:/ / www.santafe.gov.ar/hemerotecadigital/ diario $/ 11420 /$ ?page $=1$

Referencias a las resoluciones de este Congreso en relación con propuestas para la conformación de un funcionariado público formado en la universidad, para superar el sesgo "clientelar" de la burocracia estatal pueden encontrarse en: Gluck y Mutti (2009). 32 “Congreso Anual Universitario". Santa Fe, Lunes 25 de octubre de 1926. Disponible en: http:// www.santafe.gov.ar/hemerotecadigital/diario/11422/?page=1 
taria sobre los proyectos de investigación y publicaciones existentes en cada universidad. A instancias de los delegados R. Márquez Miranda, Osvaldo Loudet, León Dujovne y Alberto Palcos (ligados al reformismo), el Iv Congreso aprobó una declaración que abogaba por el desarrollo amplio de becas para facilitar los estudios universitarios "a cuantos jóvenes aptos estén en condiciones de cursar sus estudios". ${ }^{33}$

El impacto de estas experiencias probablemente resuena en el proyecto de ley sectorial que presentó el diputado Pedro Cossio ${ }^{34}$ en 1929. Respetando las reivindicaciones reformistas, Cossio incorporó un Congreso Universitario de celebración anual para "tratar temas relacionados con la vida científica de la universidad", con la idea de "uniformar la educación filosófica común de la enseñanza superior entre las diversas universidades". A diferencia de las experiencias de los Congresos Anuales que hemos descripto, el diputado restringía la participación a sólo un representante delegado por cada universidad (Art. 46), sin especificar ni su carácter ni su forma de elección. Estimar el grado en que estos Congresos pudieron influir en la política pública del gobierno de Alvear requiere profundizar la investigación. ${ }^{35}$

33 "Congreso Nacional Universitario". Santa Fe, Martes 26 de octubre de 1926. Disponible en: http:/ /www.santafe.gov.ar/hemerotecadigital/diario/11422/?page=1

${ }^{34}$ Diputado por Tucumán, Cossio presentó su proyecto cuando se desarrollaban en la UNT fuertes conflictos internos y huelgas de la Federación Universitaria de Tucumán -en manos del Reformismo - para efectivizar la participación estudiantil en el gobierno garantizada por la reforma de los Estatutos en 1924 (Rectorado de Juan. B. Terán) (Guerra Orozco, 2007).

${ }^{35}$ Diferentes protagonistas de la época evaluaron de manera diversa el impacto de sus recomendaciones. En 1926 el Ministro Sagarna afirmaría que "Pocas son las conclusiones de los congresos anteriores que han tenido, hasta hoy, una traducción en realidades y quizá tendremos que esperar algún tiempo para que ello se produzca, pero es seguro que todas las universidades argentinas tienen hoy mutuo conocimiento y aprecio, muy superior al que tenían en 1923, a la hora de la conferencia inicial..." (Sagarna, 1926:364). Al abrir las sesiones ordinarias del Congreso Nacional en 1928, el Presidente Alvear afirmaba, por el contrario que: “En el año pasado se celebró en Tucumán el Quinto Congreso Universitario Anual, iniciado y organizado por la Universidad Nacional de La Plata, terminándose, así, el primer ciclo de esas reuniones tan interesantes y fecundas; el Poder Ejecutivo estuvo en todas ellas representado y puedo afirmar a Vuestra Honorabilidad y al país que, gracias a esos Congresos, los universitarios argentinos se conocen y conocen al país mejor, que varias de sus conclusiones han sido aceptadas en actos de Gobierno, en proyectos legislativos, en planes y programas de estudios. Recomiendo a Vuestra Honorabilidad la provisión de los recursos necesarios para que esta institución perdure y se perfeccione" (Alvear, 1928: 7). 


\section{El problema y la necesidad de coordinación universitaria: su aparición como parte del desarrollo y la crisis del reformismo liberal en los planos social, político y educativo}

Al poner en perspectiva histórico-social la coordinación interuniversitaria, como objeto de debate político y de preocupación social entre 1885 y 1930 en Argentina, se observa que la cuestión se introdujo en la "agenda" universitaria formando parte de las disputas por la apertura o el cierre social de la Universidad y por la interpretación de su papel en el progreso social. El fenómeno aparece como un componente en los intentos de reforma del sistema educativo como un todo, pero también en las demandas de transformación de las formas de actuación y de diseño del aparato estatal. Es un panorama rico y diverso, con aristas que permiten enriquecer las interpretaciones centradas en la dualidad de tipos ideales "coordinación colegiada/coordinación centralizada". Hacia la década de 1930, con cinco universidades nacionales (Buenos Aires, Córdoba, La Plata, Litoral y Tucumán), se habían desarrollado ya concepciones contrastantes sobre las formas de coordinar, defendidas por grupos y sectores sociales diferenciados. Las propuestas reflejaron la crisis del régimen oligárquico y la formulación, el ascenso y el quiebre de una "solución pluralista", acompañada en el plano nacional por la disolución y la recomposición del bloque de fuerzas dominantes y, en el plano internacional, por la crisis y el reacomodamiento del capitalismo mundial entre las dos guerras. En trazos gruesos pueden reconocerse dos vertientes, portadas por:

- Grupos liberal-reformistas, que pensaron la coordinación entre las universidades a partir de principios políticos democratizadores y pluralistas;

- Fracciones asociadas al proceso de "cierre conservador" en un contexto de debilitamiento del paradigma político liberal y de avance de los diversos nacionalismos, más cercanos a formas corporativas de representación funcional.

Sus disputas reflejaron y afectaron el decurso de dos importantes procesos: el incremento de la contestación política de sectores beneficiados por una efectiva movilidad social ascendente, y la división de las clases dominantes en el plano de los intereses políticos (verbigracia, la aparición de una fracción reformista) y materiales (verbigracia, la conformación de una fracción terrateniente con intereses en la industria) (Villanueva, 1972). Se hicieron presentes argumentos sobre la necesidad de garantizar la racionalidad administrativa, de instalar algún tipo de planificación, de controlar las prioridades de asig- 
nación del gasto público y, en última instancia, de "ordenar" las actividades universitarias al servicio de un proyecto social que comenzaba a reconocer los límites del modelo agro-exportador. Dentro de ese proyecto, se comenzó a delinear una nueva forma de Estado, llamado a procesar las contradicciones de un bloque de fuerzas sociales inestable y facilitador del pasaje hacia una fase pluralista.

Al no materializarse los intentos de reforma del sistema educativo para el "cierre social" por la vía de la generación de circuitos educativos segmentados, se implementaron políticas restrictivas, con efectos evidentes en la reducción del ritmo de crecimiento de la matrícula de las escuelas medias y de las universidades. Según datos aportados por Cano (1986: 106 y ss.), en la década de 1910 la matrícula del nivel medio crecería a un ritmo promedio anual de alrededor del 10\%, mientras que en la década de 1920 lo haría a un 5.9\%, absorbiendo en 1930 a 85732 alumnos. En el nivel universitario, en los tres años que van de 1918 a 1921 - años en los que se introdujeron reformas en los estatutos de las universidades en línea con los postulados reformistas se incorporaron más de 5000 estudiantes, pasando de 8634 a 14 057; harían falta siete años para que se incorporara una cantidad semejante, llevando la matrícula durante 1930 a 20258 alumnos (19 848 en 1929).

Como hemos señalado, la coordinación universitaria apareció en este periodo como una preocupación dentro de los intentos de reforma del sistema educativo como un todo. Aspectos tales como la necesidad de criterios comunes en los sistemas de ingreso, la equivalencia de títulos, los planes y estatutos, la administración del presupuesto sectorial y la designación de docentes, entre otras responsabilidades, se pensaron por primera vez depositadas en un espacio diferenciado del PEN y de las instituciones mismas. Así, en el periodo analizado, las discusiones fundacionales respecto de la demarcación de los límites de la Universidad en o al lado del Estado (ver nota al pie número 1) se enriquecieron con debates sobre nuevas cuestiones como las prioridades de inversión en educación y los proyectos de modernización y de crecimiento universitario y nacional, coincidiendo en las críticas al perfil predominantemente profesionalista de la formación universitaria (por ejemplo, Sagarna, 1926, 365-366). Las fracciones liberales reformistas que apoyaron la reforma política en la sociedad y en las universidades enfrentadas al régimen oligárquico de dominación también adoptaron la idea de que era necesario dotar de organicidad y de articulación al sistema educativo, incluyendo a las universidades.

No obstante, si bien los proyectos de Saavedra Lamas (1916), Sullivan (1925) y Alvear/Marcó (1926) comparten la relocalización de atribuciones en la cabeza de un Consejo - en todos los casos presidido o bajo la jurisdicción 
del Ministro de Instrucción Pública -, muestran diferencias en su composición y en su articulación con la estructura del sistema de gobierno de la educación, pues corresponden a distintos proyectos sociales y políticos en el bloque de fuerzas: representación democrática amplia en el caso de Sullivan; representación con criterios político-burocráticos (participación del Senado en el proceso de conformación, equilibrio entre delegados del PEN y de las Universidades) e intentos de privatización (legalización no sólo de universidades libres sino incorporación de sus representantes en el aparato del Estado) en el caso de Marcó; o la representación combinando criterios jerárquicos y democráticos en el caso de Saavedra Lamas.

Según Sullivan y Cossio, el interés por "coordinar" se justificaba como una reivindicación democrática que permitiera ampliar las instancias de discusión sobre el papel de la Universidad en la sociedad, mantenerla "abierta" a los sectores sociales en ascenso y crear un espacio universitario común más allá de las fronteras de cada institución, permitiendo a los académicos - que comenzaban a recortarse como capa social particularizada - incidir en la definición de políticas públicas. Para Saavedra Lamas y Marcó, la coordinación parece más ligada al interés por neutralizar conflictos sociales y políticos, integrar la Universidad al aparato del Estado, resolver problemas de asignación de dinero público en momentos de crisis fiscal, así como también, en el caso de Marcó, quebrar el monopolio estatal sobre la educación universitaria, defendiendo a las fracciones conservadoras de la amenaza representada por el Radicalismo. Acompañando esos debates y propuestas, en la década de 1920 registramos las primeras experiencias de organización de espacios de discusión y de coordinación sectorial - los Congresos Universitarios - , en los que confluyeron universitarios, funcionarios y gobernantes de ambos grupos.

Estos ejes serán resignificados en la etapa que se abre con el golpe de Estado de 1930, en la que se hicieron ya evidentes cambios más generales en las concepciones y acciones del estado capitalista occidental en su transición a su forma corporativa e intervencionista. A partir de 1930, la conveniencia de una instancia de coordinación universitaria será reformulada cuando se constituya en el poder un nuevo bloque de fuerzas en el que diversos sectores y fracciones nacionalistas, conservadoras, católicas, y liberal-conservadoras avanzarán en la reestructuración de las funciones y del aparato de Estado con el objetivo de regular las nuevas condiciones económicas y políticas. A estas iniciativas, "desde arriba" (desde la cúspide del Estado), se le sumarán iniciativas defensivas, originadas por algunos colectivos que comienzan a diferenciarse al interior de las universidades: reaccionando a las restricciones presupuestarias y a las intervenciones de los gobiernos de la Década Infame, 
los rectores se constituirán en actor político colectivo, elaborando estrategias para efectuar demandas a los Gobiernos de manera unificada.

\section{Referencias}

Altamirano, Carlos (2008). Historia de los intelectuales en América Latina: los avatares de la "ciudad letrada" en el siglo xx. Buenos Aires: Katz Editores.

Ansaldi, Waldo (1991). Frívola y casquivana, mano de hierro en guante de seda. Una propuesta para problematizar el término oligarquía en América Latina. Ponencia presentada en las Terceras Jornadas Inter-Escuelas/Departamentos de Historia de Universidades Nacionales. Facultad de Filosofía y Letras. UBA, 11-13 de septiembre.

Ansaldi, Waldo (1994a). Mediaciones políticas y construcción de la democracia argentina. Estudios. Revista del Centro de Estudios Avanzados, 3.

Ansaldi, Waldo (1994b). La interferencia está en el canal. Mediaciones políticas (partidarias y corporativas) en la construcción de la democracia en Argentina. Boletín Americanista, 34 (44), Universidad de Barcelona, Facultad de Geografía e Historia.

Barsky, Osvaldo; Sigal, Víctor y Dávila, Mabel (coords.) (2004). Los desafíos de la universidad argentina. Buenos Aires: Siglo XXI.

Bergel, Martín (2006). Manuel Seoane y Luis Heysen: el entrelugar de los exiliados apristas peruanos en la Argentina de los veintes. Políticas de la Memoria, 6 (7).

Biagini, Hugo (2000). La Reforma Universitaria. Antecedentes y consecuente. Buenos Aires: Leviatán.

Botana, Natalio (1998). El orden conservador. La politica argentina entre 1880 y 1916. Buenos Aires: Sudamericana.

Buchbinder, Pablo (2005). Historia de las Universidades Argentinas. Buenos Aires: Editorial Sudamericana.

Buchbinder, Pablo (2012). Formación de los sectores dirigentes y controversias políticas en el ámbito universitario: el caso de las facultades de Derecho 18901912. Boletín del Instituto de Historia Argentina y Americana Dr. Emilio Ravigna$n i, 37$.

Busaniche, José Carmelo (1977). Antecedentes y creación de la unL. Revista Universidad, 87.

Cano, Daniel (1985). La educación superior en la Argentina. Buenos Aires: Grupo Editor Latinoamericano-FLACSO-CRESALC/UNESCO.

Cantini, José Luis (1997). La autonomía y la autarquía de las universidades nacionales. Buenos Aires: Academia Nacional de Educación.

Cattáneo, Liliana y Rodríguez, Fernando D. (2000). Ariel exasperado. Desventuras de la reforma universitaria en la década del veinte. Prismas. Revista de historia intelectual, 4.

Chiroleu, Adriana (2000). La reforma universitaria. En R. Falcón. Democracia, conflicto social y renovación de ideas (1916-1930). Nueva Historia Argentina, T. VI (pp. 359-389). Buenos Aires: Sudamericana. 
Cucuzza, Héctor (1985). El sistema educativo argentino. Aportes para la discusión sobre su origen y primeras tentativas de reforma. En F. Hillert et al. El sistema educativo argentino: antecedentes, formación y crisis (pp. 103-136). Buenos Aires: Cartago.

De Imaz, José Luis (1969). Los que mandan. Buenos Aires: EudebA.

Derisi, Octavio Nicolás (1983). La Universidad Católica Argentina en el recuerdo: a los 25 años de su fundación. Buenos Aires: Universidad Católica Argentina. Recuperado de: http://bibliotecadigital.uca.edu.ar/repositorio/libros/universidad-catolica-argentina-fundacion-derisi.pdf

Favaro, Orietta y Morinelli, Marta (1991). De la revolución del 90 al golpe del 30: el reformismo liberal en el Río de la Plata. Revista de Historia, 2 (noviembre), Facultad de Humanidades, Universidad Nacional del Comahue.

Fernández Lamarra, Norberto (2003). La Educación Superior en la Argentina en debate, Buenos Aires: EUdEBA-IESALC/UnEsCo.

Fernández, Ma. Anita; Lemos, Ma. Luisa y Wiñar, David (1997). La Argentina fragmentada. El caso de la Educación. Buenos Aires: Miño y Dávila Editores.

García, Susana V. (2000). "Embajadores intelectuales". El apoyo del Estado a los congresos de estudiantes americanos a principios del siglo xx. Estudios Sociales. Revista Universitaria Semestral, 10 (19).

García, Susana V. (2010). Enseñanza científica y cultura académica. La Universidad de La Plata y las Ciencias Naturales (1900-1930). Rosario: Prohistoria Ediciones.

Gluck, Mario y Mutti, Gastón (2009). Política de masas y eficacia gubernamental en la Argentina de los años 20': el surgimiento de los estudios de ciencias políticas en Rosario. Los proyectos de Rafael Bielsa y Juan Álvarez. Revista de Ciencia Política y Relaciones Internacionales, 2 (2).

Gómez, Teresita (1997). Planificación en Argentina ¿redefinición de un modelo de crecimiento? Estudios Sociales. Revista Universitaria semestral, 7 (12).

Gómez, Teresita (2013). La planificación en la Argentina en la primera mitad del siglo xx. En A. Muller y T. Gómez (comps.). La planificación en Argentina en perspectiva (1930-2012) (pp. 57-83). Buenos Aires: CESPA-UBA.

Graciano, Osvaldo (2003). Intelectuales, ciencia y política en la Argentina neoconservadora. La experiencia de los universitarios socialistas. Estudios interdisciplinarios de América Latina y el Caribe, 14 (2). Recuperado de: http:/ / eial. tau.ac.il/index.php/eial/issue/view/63

Graciarena, Jorge (1971). Clases medias y movimiento estudiantil. El Reformismo Argentino: 1918-1966. Revista Mexicana de Sociología, 33 (1).

Graciarena, Jorge (1985). El Estado Latinoamericano. Perspectiva. Figuras, Crísis, Prospectiva. Revista Pensamiento Iberoamericano, 5.

Guerra Orozco, Cecilia (2007). Un factor de tensión en los claustros universitarios: la participación estudiantil. Ponencia presentada en las XI Jornadas Interescuelas/ Departamentos de Historia. Tucumán, unT, 19 a 22 de septiembre.

Halperín Donghi, Tulio (1969). Historia de la Universidad de Buenos Aires. Buenos Aires: EUDEBA.

Hora, Roy (2014). La elite económica argentina, 1810-1914. Revista de Sociologia e Politica, 22 (52). 
Losada, Leandro (2007). ¿Oligarquía o elites? Estructura y composición de las clases altas de la ciudad de Buenos Aires entre 1880 y 1930. Hispanic American Historical Review, 87 (I).

Muller, Alberto (2013). Planificación: notas introductorias. En A. Muller y T. Gómez (comps.). La Planificación en Argentina en perspectiva (1930-2012) (pp. 3-34). Buenos Aires: UBA-CESPA.

Murmis, Miguel y Portantiero, Juan C. (1968). Crecimiento industrial y alianza de clases en la Argentina (1930-1940). Buenos Aires: Instituto "Di Tella". Documento $\mathrm{N}^{\circ} 49$, mimeo.

Nosiglia, Ma. Catalina y Mulle, Verónica P. (2012). Las transformaciones en el gobierno de la educación superior en Argentina: el papel del Consejo Interuniversitario Nacional en la definición de políticas Universitarias. Políticas Educativas, 5 (2).

Ortiz, Tulio (coord.) (2012). La Facultad de Derecho de la Universidad de Buenos Aires en la formación de las elites. Buenos Aires: Departamento de Publicaciones-Facultad de Derecho-UBA.

Ortiz, Tulio y Scotti, Luciana (2008). Las reformas antes de la Reforma. Primeros movimientos estudiantiles en la Universidad de Buenos Aires. Recuperado de: www. uba.ar/reforma/download/reformas.pdf

Páez de la Torre, C. (2004, 4 de julio). "1921, la Universidad de Tucumán se hace nacional". La Gaceta-Tucumán. Recuperado de: http:/ / www.lagaceta.com.ar/ nota/208959/la-gaceta-literaria/1921-universidad-tucuman-se-hace-nacional.html

Páez de la Torre, C. (2012, 23 de diciembre). "La gran huelga estudiantil de 1932". La Gaceta-Tucumán. Recuperado de: http://www.lagaceta.com.ar/ nota/526471/sociedad/gran-huelga-estudiantil-1932.html

Persello, Ana V. (2009). De las juntas y comisiones al Consejo Nacional Económico. La administración pública en los años 30. Trabajo presentado en el Instituto de Desarrollo Económico y Social/Saberes del Estado y Elites Estatales. Recuperado de: http:/ / saberesdeestado.ides.org.ar/archivos/208

Persello, Ana V. (2001). Administración y política en los gobiernos radicales, 1916-1930. Sociohistórica, 8.

Persello, Ana V. (2000). Los gobiernos radicales: debate institucional y práctica política. En R. Falcón. Democracia, conflicto social y renovación de ideas (19161930). Nueva Historia Argentina, T. VI (pp, 59-100). Buenos Aires: Sudamericana.

Portantiero, Juan C. (1978). Estudiantes y política en América Latina. El proceso de la reforma universitaria (1918-1938). México: Siglo XXI.

Puiggrós, Adriana (1996). Sujetos, disciplina y curriculum en los orígenes del sistema educativo argentino (1885-1916). Historia de la Educación Argentina I, Buenos Aires, Editorial Galerna.

Rodríguez, Fernando D. y Vázquez, Karina (2002). Gritos y susurros en el jardín de Akademus. El movimiento estudiantil reformista en La Plata a través de sus revistas (1923-1927). Intellèctus Revista Eletrônica, I (2). Recuperado de: http://www.intellectus.uerj.br/ 
Rojkind, Inés (2007). Estudiantes, universidad y politica en el Buenos Aires del novecientos. Ponencia presentada en las XxI Jornadas Inter-escuelas/Departamentos de Historia. Tucumán: UnT, 19 a 22 de septiembre.

Romero, Ricardo (2004). Reformismo y Universidad. En H. Biagini et al. El pensamiento alternativo en la Argentina del siglo xx. Tomo I, Identidad, utopía, integración (1910-1930) (pp. 233-242). Buenos Aires: Biblos.

Ruvituso, Clara (2008). Política universitaria y campo académico. Un estudio centrado en la trayectoria del área de filosofía de la Facultad de Humanidades y Ciencias de la Educación de la UNLP (1920-1955). Ponencia presentada en las v Jornadas de Sociología de la unLP. Universidad Nacional de La Plata. Facultad de Humanidades y Ciencias de la Educación. Departamento de Sociología, La Plata. Recuperado de: http://www.aacademica.com/000-096/44/691

Saguier, Eduardo y Meabe, Joaquín (2013). Arqueología del mandarinato y de la nomenklatura académica. Absolutismo, Ilustración, Reforma y Contra-Ilustración en el Río de la Plata y en Argentina (1600-2012). Buenos Aires: Lugar.

Sánchez Martínez, Eduardo (2003). La Legislación sobre Educación Superior en Argentina: entre rupturas, continuidades y transformaciones. Buenos Aires: UNESCO/ IESALC.

Sartelli, Eduardo (2011). Las bisagras de la historia. La Argentina, de la Colonia a la Revolución. En Eduardo Sartelli (comp.). La crisis orgánica de la sociedad argentina (pp. 3-12). Buenos Aires: EfyL.

Suasnábar, Claudio (2009). La Reforma Universitaria de Córdoba: una mirada histórica de la relación entre intelectuales, universidad y política en la Argentina. Praxis Educativa, 4 (1).

Tanzi, Héctor José (2005). Historia ideológica de la Corte Suprema de Justicia de la Nación (1930-1947). IUSHISTORIA Revista Electrónica. Recuperado de: www. p3.usal.edu.ar/index.php/iushistoria/article/viewFile/1648/2081

Tedesco, Juan C. (1986) [1970]. Educación y sociedad en la Argentina (1880-1945). Buenos Aires: Ediciones Solar.

Terán, Óscar (2000). Vida intelectual en el Buenos Aires fin de siglo (1880-1910). Derivas a la "cultura científica". Buenos Aires: FCE.

Vallejo, Gustavo (2001). "El culto de lo bello". La universidad humanista de la década del '20. En H. Biagini. La Universidad de La Plata y el movimiento estudiantil, desde sus orígenes hasta 1930 (pp. 113-152). La Plata: unLP.

Vera de Flachs, Ma. C. (2006). Contrarreformas y movimientos estudiantiles en la Universidad de Córdoba (1870-1936). En Renate Marsiske (Coord.). Movimientos Estudiantiles en la Historia de América Latina III (pp. 21-80). México: Plaza y Valdés Editores.

Vignoli, M. (2004). La nacionalización de la universidad durante la gestión radical de Miguel Campero (1935-1939). Actas del II Congreso sobre la Historia de la Universidad. Recuperado de: http://www.2historia.unt.edu.ar/index.php/ actas-primer-congreso

Villanueva, Javier (1972). El origen de la industrialización argentina. Desarrollo Económico, 12 (47).

Vior, Susana; Misuraca, Ma. Rosa; Más Rocha, Stella M. (2001). Radicalismo y educación: 1916-1930. Ponencia presentada en el IV Encuentro Internacional de Historia de la Educación. Morelia-México. 
Vior, Susana; Misuraca, Ma. Rosa; Más Rocha, Stella M. (2004). La Nación, el Estado y la educación: entre el liberalismo social y el liberalismo conservador. Ponencia presentada en Congreso Internacional "Educación, lenguaje y sociedad". Tensiones Educativas en América Latina, unLPam, Argentina. Recuperado de: www.fchst.unlpam.edu.ar/iciels/078.pdf

Zimmermann, Eduardo (1992). Los intelectuales, las ciencias sociales y el reformismo liberal: Argentina, 1890-1916. Desarrollo Económico, 31 (124).

Zimmermann, Eduardo (1995). Los liberales reformistas. Buenos Aires: Sudamericana.

Zimmermann, Eduardo (1998). La prensa y la oposición política en la Argentina de comienzos de siglo: el caso de “La Nación" y el Partido Republicano. Estudios Sociales, 15 (1).

\section{Fuentes Documentales}

Alvear, Marcelo T. (1928). Mensaje del Excmo. Señor Presidente de la Nación, Marcelo T. de Alvear al inaugurar el período ordinario de sesiones del H. Congreso Nacional. Buenos Aires: Talleres Gráficos del Ministerio de Agricultura de la Nación.

Dirección de Información Parlamentaria (2010). Educación Superior. Antecedentes para la Reforma. Buenos Aires: HCDN-Secretaría Parlamentaria.

Congreso Nacional (1899). Cámara de Diputados. $9^{\circ}$ Sesión Ordinaria del 5 de Junio de 1899. Buenos Aires: Congreso Nacional.

El Tercer Congreso Universitario (1926). Crónica Universitaria. Revista de la UNC. 13 (1-3, enero-marzo).

Lugones, L. (1903). La reforma educacional. Un ministro y doce académicos. Buenos Aires: s/r.

Nazar Anchorena, Benito (1926). Discurso de apertura del Tercer Congreso Universitario Anual. Córdoba. En: El Tercer Congreso Universitario Anual. Discursos. Revista de la Universidad Nacional de Córdoba, 13 (1-3 enero-marzo).

Periódico "Santa Fe", años 1925 y 1926.

Saavedra Lamas, Carlos (1916). El gobierno educacional. Discurso del Ministro de Justicia e Instrucción Pública en la apertura de los cursos de la Universidad de La Plata. 25 de abril de 1916. Buenos Aires: Imprenta de Coni Hermanos.

Sagarna, Antonio (1926). Discurso pronunciado en el acto de inauguración del Cuarto Congreso Anual Universitario en Santa Fe. En: VERBVM, Revista del Centro de Estudiantes de Filosofía y Letras. Universidad de Buenos Aires. 
